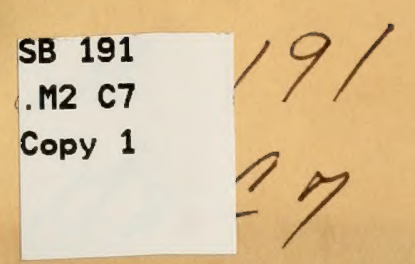


Hollinger Corp. pH 8.5 
U. S. DEPARTMENT OF AGRICULTURE. BUREAU OF PLANT INDUSTRY_BULLETIN N0. 141, PART IV.

B. T. GALLOWAY, Chief of Bureau.

\section{THE IMPORTANCE OF BROAD BREEDING IN CORN.}

$\mathrm{BY}$

G. N. COllins, Assistant Botanist.

ISSUED JUNE 4, 1909.

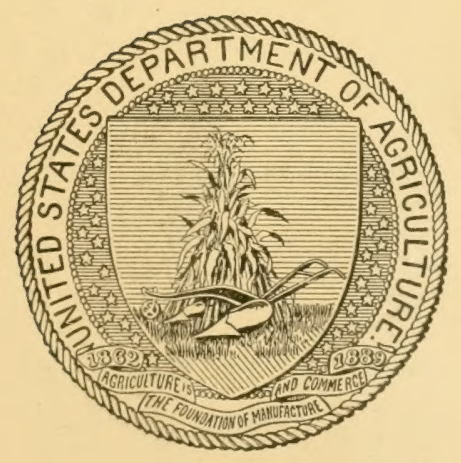

WASHINGTON:

GOVERN MENT PRINTING OFEICE.

1909 . 
D. of De

$\because \vdots$ 


\section{CONTENTS.}

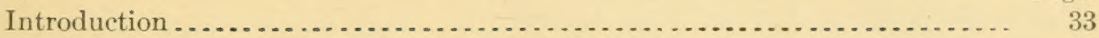

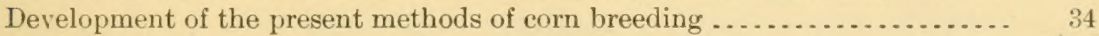

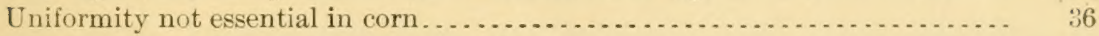

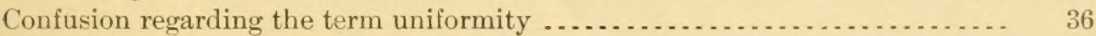

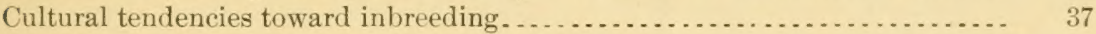

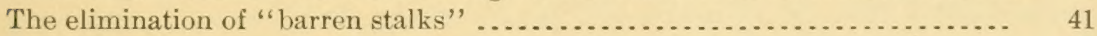

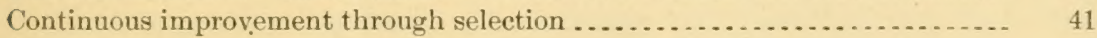

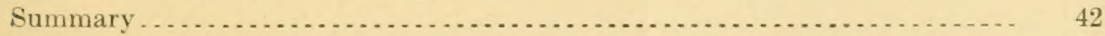

141-IV 

B. P. I. -468 .

\section{THE IMPORTANCE OF BROAD BREEDING IN CORN.}

By G. N. Collins, Assistant Botanist.

\section{INTRODUCTION.}

A study of the primitive types of corn and the history of the more productive varieties affords many indications, that the improvement of our varieties is being checked by the injurious effects of inbreeding and that a further advance can best be secured by more fully satisfying the natural requirement of cross-fertilization. The conspicuous increase in yield that results from the crossing of distinct varieties and the rapid deterioration that follows self-pollination strongly support this view. Unfortunately the more recent changes in the methods of breeders have not been in the direction of better provision for cross-fertilization, but toward a still closer approach to self-pollination, the attempt being made to apply to corn theories and methods derived from plants naturally adapted for self-fertilization.

Until recently, the study of evolution and heredity has had little effect on the methods employed by breeders of domesticated plants and animals. Improved varieties were developed before Darwin's time in much the same way that they have been since. Whether the doctrines of Darwin or those of Lamarck, Naegeli, Weismann, or Cope should be accepted as giving correct interpretations has seemed to be a purely academic question from the standpoint of the practical breeder.

It is entirely different with the recently elaborated theory of De Vries. Converts to this new hypothesis have not been slow to claim that it has an important practical bearing, especially when taken in connection with the facts of Mendelism. Serious changes in the methods of breeding are being urged that are likely to have very injurious effects if they are generally applied to our varieties of Indian corn.

The definite mechanical character of these theories and the facility with which they appear to explain some of the facts of heredity render them very convincing. There is a tendency to forget their limitations and overlook the fact that whatever their value with 
close-fertilized plants like wheat they are entirely inapplicable to a cross-fertilized plant like corn.

The popularization of the new theories has continued until they are now not only urged as a basis for scientific experiments in breeding, but are even recommended as a guide for the practical farmer. It is assumed that uniformity is a normal condition. New "elementary species" are supposed to originate by sudden changes and then to remain uniform, so that no further change is possible after a "pure strain" has been isolated, until new mutations occur. If these theories were correct, then it would be true, as De Vries maintains, that the breeder is wasting time in attempting to ameliorate varieties by the continued selection of minute variations after the elementary species have been isolated.

The hundreds of improved forms of domesticated plants which have been derived and maintained by. continuous selection through long periods of time sufficiently refute the claim that selection is ineffective and should warn breeders from the danger of abandoning too soon a system which has yielded such brilliant results. As applied to corn the De Vriesian doctrine is particularly dangerous, since it would replace the already close selection by a method of still narrower breeding, the nearest approach to self-fertilization that is possible with a cross-pollinated plant.

Independent of these theories, many corn breeders have been aiming at uniformity, and such will doubtless welcome this apparent justification. It is perhaps fortunate for the progress of corn breeding that the wide promulgation of these theories has been delayed until the fallacy of the system of close breeding is beginning to be appreciated and the more thoughtful and observant of our corn breeders are viewing with distrust the system of close selection and are casting about for an alternative method.

\section{DEVELOPIIENT OF THE PRESENT IMETHODS OF CORN BREEDING.}

Stated broadly, the object of breeding field corn is to produce varieties that will give the largest yield of grain under given conditions. The latitude allowed by this simple object gives the corn breeder an advantage over the breeder of more specialized cropsan advantage which has not been fully appreciated. The varieties of sweet corn fall more nearly in the class with vegetables, and the many special requirements, such as taste, appearance, and uniformity make their improvement a much more complicated and very different problem from that of the improvement of field corn. With field corn the development of varieties with special qualities will not become an important consideration until the possibilities of corn as a human food are much more fully appreciated than at present. 
In the early stages of corn breeding it was thought sufficient to select the largest and best-filled ears for seed. With the idea that like produces like, this was obviously the way to increase the size of the ear. It was soon found that some of the plants that produced large ears had undesirable characteristics and selection was moved from the crib to the field.

The next stage was reached when it was realized that, though the ear was large and well filled and the plant had no objectionable features, some of the plants failed to reproduce their desirable characteristics in subsequent generations. The finest plants are sometimes due to particularly favorable locations in the field rather than to inherent superiority. This led to the study of the behavior of the progeny of particular ears before deciding whether they were worthy of being used as the foundation of new varieties, and the so-called "ear to row" method of selection was developed. These more laborious methods of breeding have all operated to limit the number of individuals tested and to restrict the crossing.

The increased yields which follow an intelligent application of this method of selection when applied to an unimproved stock have caused two important factors to be largely overlooked: (1) The number of plants from which careful selection can be made by any one person is reduced from thousands to hundreds with a correspondingly reduced chance of securing the individuals really superior as breeders; (2) these methods restrict the free crossing that is normal to the species, unless accompanied by the extremely laborious method of hand-pollination, which still further reduces opportunity of selection and renders the method inadequate, except where experiments are conducted on a very large scale, beyond the reach of the average farmer.

It has long been known that self-pollinated ears yield plants of greatly reduced vigor, and that a few generations of self-pollination usually result in sterility. Yet in spite of this obvious danger sign, nearly all of our corn breeders have continued to produce varieties with the narrowest possible foundation, often by using a single ear as the basis of the new variety and taking measures to prevent the bringing in of any new strains for fear of contamination.

Had corn breeding developed independently the danger from narrow breeding would doubtless have been more fully appreciated, but modern corn-breeding methods have been largely adapted from methods that have proved successful with other crops, such as wheat, oats, and barley, in which self-pollination is the rule. With self-fertilized species it is as safe to start a variety from a single plant as it is to start a variety of apples from a single bud. Furthermore, these autogamous strains tend to show great varietal uniformity, and the $141-\mathrm{IV}$ 
degree of this uniformity is regarded as the measure of the purity of the strain. With corn, conditions are different. It is normally interbred and normally exhibits considerable diversity in conspicuous characteristics-diversities difficult to suppress even when the closest selection is practiced.

\section{UNIFORMITY NOT ESSENTIAL IN CORN.}

In the cultivation of many plants varietal uniformity is a prime requisite, and with plants where seed is not the part for which the crop is grown this uniformity may be secured by narrow inbreeding and narrow selection, without imminent danger of deterioration. With many plants a reduction in the quantity of seed or in its germinating power is of relatively small importance. Close breeding may be necessary and permissible in such crops as beets, cabbage, lettuce, or tobacco, where uniformity in vegetative characteristics is required. It may be profitable to produce uniform varieties of chickens, dogs, or ornamental plants, even though such varieties may be short lived. But the fancier's methods are not applicable to field crops. The corn grower receives a relatively small part of his profits in the form of prizes awarded on the score-card method of "point ratings," yet, except for the seedsman, this is the only monetary advantage in producing corn with perfectly uniform ears. That a corn planter should occasionally drop four or five grains instead of three in a hill is about the only reason that can be given for insisting upon uniformity in shape and size of kernels, and an occasional white speck in the yellow corn meal is advanced as sufficient warrant for the careful elimination from yellow varieties of all ears with white cobs. The desire for uniformity does not always have even these excuses. It is even urged by some breeders that the tassels and silk must be uniform in color, that the ears must be uniform in shape, with a fixed number of grains to the inch. There is not even a fancied pecuniary advantage in this, but it is held that diversity in even these unessential characteristics stamps a variety as mongrel and therefore undesirable.

Even the universal insistence upon large ears may not always be advisable, for it has resulted in the development of plants bearing single ears instead of the two or more ears that are normal to the species. Where the season is short the limitation to a single ear is a decided advantage, but under other conditions a plant producing two or three ears of moderate size may yield a quantity of shelled corn that sufficiently exceeds that on a single large ear to more than offset the additional cost of harvesting.

\section{CONFUSION REGARDING THE TERM UNIFORMITY.}

A misunderstanding regarding the meaning of the term uniformity has done much to spread the practice of inbreeding and has $141-1 \mathrm{~N}$ 
worked great injury to the cause of corn improvement. To the few successful breeder's who have produced varieties of lasting value uniformity has not signified an identity of measurable characters. but is a kind of similarity of expression, so to speak, by which the breeder recognizes a family resemblance, much as we recognize the relatives of our intimate friends, although at a loss to indicate wherein the resemblance lies. Thus to an experienced brester two ears of corn, with measurable characters that coincide as closely as possible, will immediately be recognized as belonging to different types. The ears and grains may be of the same size and shape. the color and indentation the same. yet to the practical breeder the two ears would appear to be lacking in uniformity. (onversely. ears which are obviously dissimilar in these particulars will promptly be recognized as belonging to the same strain.

The score card was an attempt to reduce this intimate and almost intuitive knowledge of the practical breeder to an exact science for wider application. but it has prover al lamentable failure-lamentalble because it gave rise to the idea that the uniformity of score-card ratings was the kind of uniformity which sucessful breeders considered essential to valuable trains of corn. and becallse miformity in score-card ratings can only be secured by rigid inbreeding.

\section{CULTURAL TENDENCIES TOWARD INBREEDING.}

The cultivation of corn is of rely great antiquity in America. and the cultural operations to which it has been subjected from the arliest periods have differed radieally from those applied to other (rops. With primitive people the seed of other cereals is maroidably mixes in planting, but corn is usually stored on the cob and the ears used for seed are carried into the fields at the time of planting. and the

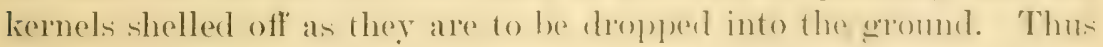
the plants from the same parent ear grow up together, and with most primitive tribes, though the planting may be considerable in the acgregate, the individual fields are in mo-t rases of small that one or two ears will often suffice for the entire field. 'The opportunity for crossing is thus very slight. It would be natural for even the most primitive man to select for seed the largest ears or those that particularly canght his fancy and the same tye wombl he seledent year after year. The seed ears also figure in many religious cere-

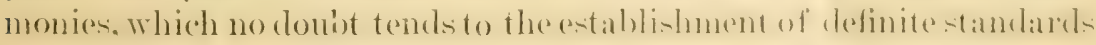
of selection.

It is universally believed by the Indians of Central America that the varieties of corn in each locality are he-t aclapted to that locality. and that other varieties brought in from other regions never yield

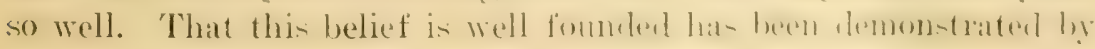
$141-15$ 
the numerous experiments of European settlers in tropical America, who are prone to regard as superstition this native belief and to import improved varieties from more or less distant localities. The failure is usually so complete the first year that the experiment is abandoned. This abnormal behavior of corn under new conditions intensifies the alo-e loreeling, and the close breeding in turn operates acrint the interehange of vareties by making the adjustments to the particular environment more delicate. 'That these primitive systems of breeding have not been indiscriminate is shown by the great number of well-defined types that exist among the Imerican aiborigines.

Among a number of primitive tribes where the cultivation of corn luan rearlied a high state of develomment. the injurions effect of this

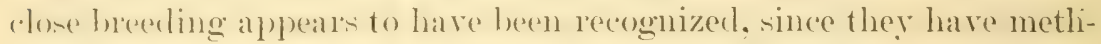
ols of guarding against it. Thus the Indians in the region of Queraltemango. in western (ruatemala, and the IIopi Indians of Irizona make a regular practice of placing seeds of more than one local variety in each hill, with the idea that larger yields can be obtained in this way.

The rery general fact that the immediate effect of crossing two closely bued train is to increase the rigor is well exemplified in corn. Although this increased vigor of first-generation hybricls is well recognized by many practical corn breeders, the value of the fact has

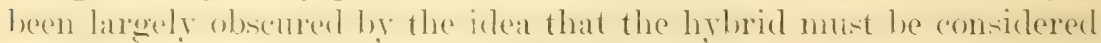
as a new variety and that uniformity must be secured before the results could have general application. To attempt to establish uniformity by a new course of selective inbreeding is to sacrifice the vigor gained by crossing.

Attention has been so persistently centered on the production of new and miform strains that the yield and vigor of the first generafion of livluid plants as eompared with the parents is seldom reported. In all the cases that have come to our attention the yield of the hybrid has been in excess of the average of the parents. Fire cases reported hy Morrow and Gardner, of the Illinois Igrienltural Experiment Station, gave increases over the average of the parents running from 1.9 per cent to 28 per cent, with an average increase of 14 per cent. McClure, ${ }^{b}$ of the same station, also reports on 12 different hybrids of sweet, pop, soft, and flint rarieties; 10 showed an increase in the weight of the ear in the first generation over the average of the parents. and one of the exceptions is explained by the author as being due to unfavorable situation, the decrease in the

a \ortow, G. E., and Gardner, F. D, Bulletin 25, Illinois Anricultural Experiment Station, 1). 179. 1893.

b McClure, (i. W. Bulletin 21, Illinois Agricultural Experiment Station, p. $\$ 2$. 1892.

141-1V 
other case being tof per cent. while the arerae increare for the whole series of 12 crosses is 16 per cent, running as high as 52.8 per cent.

If similar increases had been secured by any change in cultural methods, experiments to determine the range of applicalility of the new method would have been promptly inaugurated and the true value of the facts ascertained. Although the fact has long been established that significant increases can be -extred hy arome. we are still without knowledge regarding the condition- nex-sily for this increase. It is to be expected that the increase will be greatest between strains that have been dosely selected. but there is no direct evidence on this point. TVe should also lose no time in securing information regarding the amount of difference that shomlil exi-t between the strains crossed to secure the maximum increase of rigor. There is a wide and almost mutonched field in this linestion that will require an enormous amomnt of experiment and observation luefores justice will have been accorded to this possibility.

The definite and well-known facts that self-fertilization of corn ineritably leads to sterility and that the yedel can he incearsed by the crosing of valieties have not heres sullicient to attlatet attention in the dangers of inbreeding and close selection. No middle course between the indiscriminate planting of the oweral run of real and the rigid selection of a definite type seems to have been seriously considered. IIad it been realized that diver-ity i- a necensury to the life of the sjeceses as is chlorophyll to the life of the individual plant. it would have been evident that one might as well hrext to oliminate the green color from the leaves as to suppress this normal rariation.

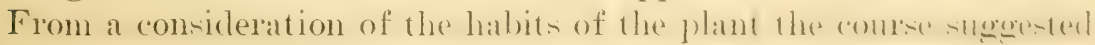
in undertaking the improvement of corn would be to seek the best methods for continuing to combine distinct strains. thus ntilizing the increased vigor and productireness resulting fon their interbreeding.

While the crossing of our more or less inbred rarieties mat confidently be expected to result in increased rigor and fertility, it is hardly to be expected that the full amount of the increase in yield

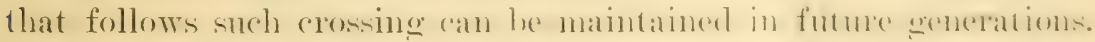
The probability is that a part of the increased fortility of the hy-

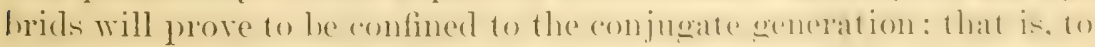

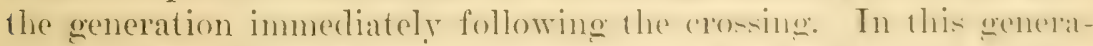

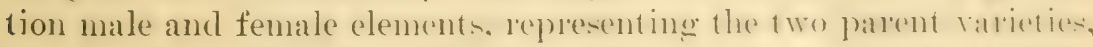
are present in the nuclei of the plant, but have not completed the process of conjugation, with the result that a sort of protoplasmic

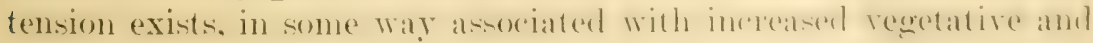
geproductive actirity. ${ }^{a}$ There is rood reason to believe that this is

${ }^{a}$ Cook, O. F., and Swingle, W. T. Erolution of Cellulal Struetures. I3ulletin S1, Bureau of I'lant Industry, L. S. Department of Igriculture. 1905.

$141-:{ }^{\circ}$ 
the care in certain cotton hybrids, and if it should also prove to be an important factor in the increased yields of corn hybrids the rewalts would warrant the production of hybrid seed in a breeding plot each year for field planting the following year. To secure hyluid seed it would only he necessary to plant two distinct varieties in alternate rows, detasseling one rariety and using the seed from the detasceled variety for the next year's general planting. Seed from the variety that was not detasseled would not be mixed and selections could be made to supply the breeding plot for the two following years. By detasseling the other variety in the next year a stock of pure seed of this also could be grown. By this system of alternation pure stocks of seed of the two rarieties could be mainiamed. There would be produced every year a stock of hybrid seed for the ficld planting of the next year and a stock of pure seed of one of the varieties for planting the seed plots of the two following years.

The same result could be approximated by planting in the same way and detasseling one of the varieties in one half of the field and the other variety in the other half of the field. By this method seed of both the varieties would be secured each year, but there would be considerable indiscriminate crossing.

The fact that corn is wind-pollinated makes the continual production of conjugate or first-generation hybrids on a commercial scale immensely more practicable with corn than with any other field crop.

In still another way the artificial crossing of two varieties may be expected to increase the yield. With such hybrids none of the seed is self-pollinated, while with the crop grown in the usual way the percentage of self-fertilized grain must be very considerable. In most of our varieties the natural proterandrous tendeney of corn has been reduced, until under ordinary climatic conditions the pollen of nearly every plant is still being shed when the silks become receptive. Unless the wind is blowing when the pollen is shed a large amount of relf-pollination in inevitalule. It is to be expected, therefore, that any method of treatment that would eliminate or reduce this selfpollination would result in an increase of the rigor and yield of the reulting corn plants, even withont hybridization. The use of detasseled plants for the production of seed may thus be found worth while, quite apart from the question whether detasseled plants themselves yield more than those that are not detasseled.

Whatever may be the true explanation of the increased fertility of liybrid corn plants, the fact remains that larger yields of corn can be secured in this way. The study of the methods by which these important factors can be made most effective hould at least receive a place by the side of the study of elementary species and the quest of uniformity. 


\section{THE ELIMINATION OF "BARREN STALKS."}

Another factor which has worked toward the inbresling and ronsequent deterioration of highly bred varieties of corn is the removal of the so-alled "barren stalls.". The elimination of nonproductive plants is undoubtedly decirable, but the remoral of barren stallie ats usually practiced is not a step in this direction. I truly barren stalk is one that fails to produce seed. So far as the seed is concerned, therefore, this elimination is antomatic and inevitable. but it hat been urged that the barren stalks must be removed before they produce pollen, on the theory that pollen from barren stalks is likely to cantere deterioration in the progeny of neighboring plants. There this practice is followed it results only in the detasseling of all proterantrous plants, for. as pointerl out by Soule and Vanatter." it is imporsible to distinguish the truly barren plants at the time of tasceling. With many varieties. especially thowe which have not been subjocterl to rigid selection, some of the plants which erentually prove to be the most prolific show only small prudiments of ear's at the time of tasseling. The continued removal of such plants remults not in the climination of barren stalks, but in the elimination of the plants: which possess a valuable adaptation to avoid self-pollination. This. weeding ont of the more proterandrous individuals has besen cont inned with some varieties until the majority of the plants produce staninate and pistillate flowers at the same time. Then these varietien flower in comparatively still weather, there must he a large proportion of solf-pollinated seed and a conserquent weakening of the variety. This persistent tendency to proterandry can be thought of as a niturial reaction of the species against the danger of extinction from inluerel. ing. Even the true barren stalks might represent a fenclency on the part of the plant to become eliorecions. In localitien with very short seasons it may be well to discriminate against the tendency in the plant to put out ears too long after the tassel has matured, but elsewhere the avoidance of self-pollination is more important.

\section{CONTINUOUS IMPROVEMENT THROUGH SELECTION.}

The fact that narrow breeding in corn results in a recluction of vigor has remained malppreciated latrely hecanter natrow hreeding is always accompanied by selection for yield and vigor. The two procesces are opposed, so that movement in either direction is matsient and counteracted. Varieties thus produced are delicately adapted

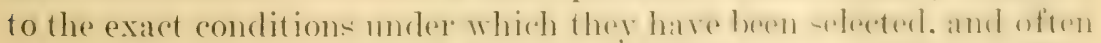
show marked deterioration when placed moler new anditions. The very delicacy of the adjustment helps to insure the much desireal

a Bulletin 165. Virginia Agricultural Experiment station. 
uniformity, for with any change of characters the debility of the stock becomes mone manifest and the elimination of the rariant individuals is certain. Increased yields are obtained by making the viedd of the individual plants more uniform, even when the full possibilities of production are not approached. The best plants of a highly bred rariety are not conspicuously more prolific than the best individuals in fields from unselected seed. ${ }^{a}$

This failure of varieties to continue to improve in vigor and fertility under continuous selection gives apparent support to the idea of De Vries that the initial selection of "pure strains" is the only progress that can be expected. It has already been seen that attempts to secure increased rigor by chose selection are impeded by the weakening effects of inbreeding. When selection is not hampered in this way, but is directed to characters not dependent on vigor and fertility, and consequently not affected by inbreeding, continuous progress may be made. Thus in the selections made by Hopkins for high and low protein content, rapid and continuous progress was made and an extreme was reached far in excess of anything observed in the original sample. The last reports show that the plants were no more uniform with respect to the-e character than at the beginning of the experiment. ${ }^{b}$

Thongh necesinty impeded hy inloreeding, important advancein yield have been made by means of close selection, but the value of these improvements hould not be allowed to obsenre the fact that the full posibilities of production are not reached until the increment of vigor obtained by crossing has been added. Even if the yields obtainable by crossing were not larger than those to be secured by peristent close selection, it is easier to permit crosing than it is to provide the very careful and skillful selection required to maintain high yields without crossing. To une crosing as a means of sustaining fertility, insteal of relying upon selection alone, would also keep our stocks in more normal physiological condition, more resistant to disease, and less liable to injury by adverse conditions.

\section{SUMMARY.}

The derelopment of the present methods of corn breeding has resulted in greatly limiting the number of inclividuals that serve as a foundation for improved strains. The danger of this course, as

${ }^{a}$ It has recently been pointed out by $\mathrm{Mr}$. O. F. Cook that the apparent adrantage of selection is greatest in degenerating stocks. See Bulletin 146, Burean of Plant Industry, U. S. Department of Agriculture. "The Superiority of Line Breeding Over Narrow Breeding."

${ }^{b}$ Smith, L. H. Ten Generations of Corn Breeding. Bulletin 128, Illinois Agricultural Experiment Station. 1908.

$141-\mathrm{IV}$ 
shown by the sterility of self-pollinated plants, has been unheeded, largely because theories and methods have been carried over to corn from other crops which are normally self-pollinated or where a high degree of uniformity is essential.

Great uniformity is of little or no economic value in corn varieties, and since it can be acquired only through close breeding it is actually undesirable to the grower. The natural requirements of cross-pollination make the problem of corn improvement entirely different from that of most of our cultivated plants.

Selection for increased yield with the maximum instead of the minimum of cross-breeding seems never to have been tried as a scientific experiment. On the other hand, the farmers of our corn-growing regions have practiced a system of broad breeding by choosing many ears from widely scattered plants in large fields and mixing the shelled corn before planting. Much of the basic improvement of our corn varieties may be ascribed to this system of increasing and maintaining vigor and fertility.

An effort to reduce the intimate intuitive knowledge of the successful breeder to measurable characters has led to the development of the score card. Instead of accomplishing the desired result, the score card has operated to intensify the closeness of selection, since uniformity in formal characters can be secured only by close breeding.

Although the methods that obtain among the primitive tribes of corn-growing Indians indicate that corn has been subjected to narrow breeding from remote times, the more intensive form of narrow breeding has been practiced for little more than a decade, yet the debilitating effects of this method are becoming apparent.

That corn is benefited by additional crossing, even when grown by primitive methods, is indicated by the custom which some tribes have of regularly mixing distinct strains to increase the yield.

It is abundantly demonstrated that the crossing of distinct varieties gives increased yields. ${ }^{a}$ With the idea that only uniform varieties could be of value the practical importance of this fact has been overlooked and the gain has been limited by subsequent inbreeding of the

${ }^{a}$ After this report was submitted in January, 1909, an article appeared by Dr. E. M. East, of the Connecticut Agricultural Experiment Station (see American Naturalist for March, 1909), describing additional instances of increased yields of corn hybrids. Thirty different crosses between varieties were grown in comparison with the parent varieties, with the result that "In erery case an increase in vigor over the parents was shown by the crosses." In the four cases in which the yields were measured the product of the hybrid exceeded that of either parent, the increase of the hybrids over the parents averaging 77 per cent. Doctor East also considers the practicability of producing hybrid seed for commercial plantings and outlines a method practically identical with that suggested here. 
hybrids. Should the increased yield of hybrid plants prove to be greatest in the first generation or should the complete elimination of self-fertilization prove an important factor, it is quite practicable to maintain a continuous supply of hybrid or cross-pollinated seed.

A study of the habits of the plant from the standpoint of crossfertilization makes apparent the nature of the so-called "barren stalks," which may be thought of as an adaptation to avoid selfpollination. The elimination of these proterandrous plants results in increasing the percentage of self-pollinated plants and is a practice of doubtful value.

The ill effects of inbreeding and selection for increased yield and vigor have tended to neutralize each other, and the consequent lack of continued improvement has lent color to the idea that continuous selection is ineffective. With characters that are not affected by decreased vigor continuous advance has been made by selection.

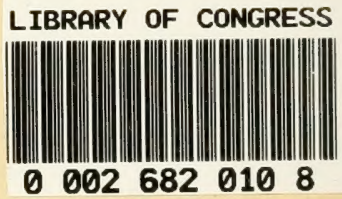


||||||||||||||||||||

000

Holli

F 


\section{LIBRARY OF CONGRESS}

|||||||||||||||||||||||||||||||||||||||||||||||

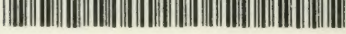

000268 20108

Hollinger Corp. pH 8.5 